\title{
Collaborative Planning and Shared Decision Making in Biosecurity Emergency Management ${ }^{+}$
}

\author{
Suzy Perry * and Rebecca Laws \\ Department of Agriculture and Fisheries, Dutton Park, Queensland 4102, Australia; \\ Rebecca.Laws@daf.qld.gov.au \\ * Correspondence: Suzy.Perry@daf.qld.gov.au \\ + Presented at the third International Tropical Agriculture Conference (TROPAG 2019), Brisbane, Australia, \\ 11-13 November 2019.
}

Published: 17 January 2020

\begin{abstract}
Robust planning and decision making processes are essential to manage biosecurity risks, particularly in emergency response situations that are highly complex, often contentious and can change rapidly. Effective risk management involves analysing large amounts of diverse scientific, technical and practical information; and dealing with competing priorities and conflicting interests amongst stakeholders. Furthermore, Australia's biosecurity system relies on shared responsibility, where governments, industry and the community work together to manage biosecurity risks. For shared responsibility to be successful, improved planning and decision making processes are required to ensure that decision making processes enable input from stakeholders. Stakeholder input into risk assessment and the development of risk management options results in more rigorous 'risk-informed' decision making. We have developed a collaborative planning and shared decision making framework for risk-informed decision making in biosecurity. It is an integrated system that incorporates principles for involving stakeholders in risk analysis (including risk assessment, management and communication), good decision making and risk governance. We will present the application of the framework during the incursion of the tropical race 4 (TR4) strain of Panama disease in north Queensland, Australia where growers and other industry stakeholders were involved in the development and implementation of the risk mitigation during the emergency response. The collaborative planning and shared decision making framework enables end-users to better manage biosecurity risks, with a logical and analytical planning and decision making process that integrates scientific, technical and practical knowledge and accounts for the political, social and economic values of stakeholders.
\end{abstract}

Keywords: risk-informed decision making; biosecurity; emergency management; risk management; shared responsibility

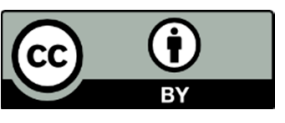

(C) 2020 by the authors. Licensee MDPI, Basel, Switzerland. This article is an open access article distributed under the terms and conditions of the Creative Commons Attribution (CC BY) license (http://creativecommons.org/licenses/by/4.0/). 